\title{
Psychogenic movement disorders: an unusual presentation in childhood with improvement after placebo test
}

Distúrbio de movimento psicogênico: uma apresentação incomum na infância com melhora após teste com placebo

Rosana H. Scola, Paulo J. Lorenzoni, Cláudia S. K. Kay, Hélio A. G. Teive, Isac Bruck, Lineu C. Werneck

Psychogenic movement disorders (PMDs) are rarely reported in childhood and their clinical manifestations may be different from those of adults ${ }^{1,2,3}$. A diagnosis of PMDs was made in a 12-year-old girl who presented dropped head, involuntary limb movements and gait disorder (Figure A). We performed a placebo test, which resulted in marked and complete improvement of symptoms within three days (Figure B). Psychogenic dropped head, especially associated with other movement disorders, has not yet been reported in children ${ }^{2,4}$. Although assessment of PMDs can be complex in childhood, our case showed that assessment of clinical features combined with therapeutic intervention (placebo test) may be useful for PMDs diagnosis ${ }^{1,3,5}$.
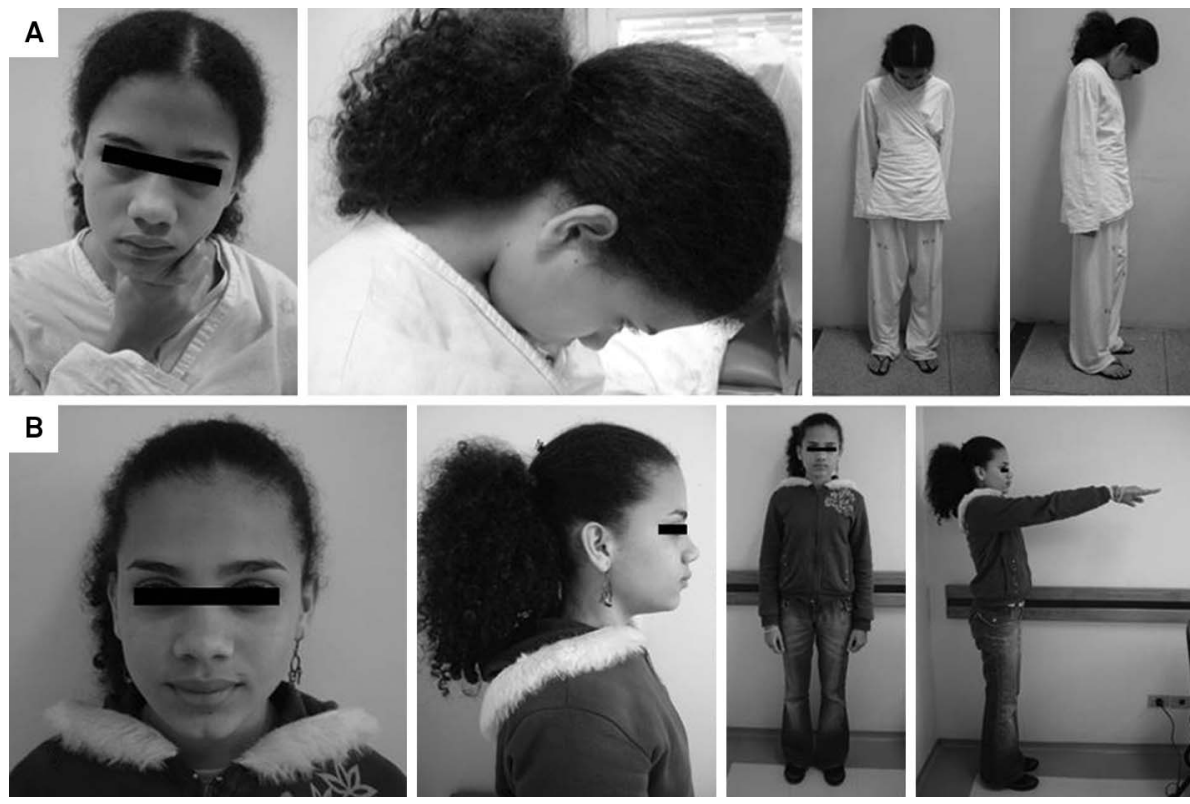

Figure. Initial clinical manifestation: dropped head in the anterocollis position (A). After three days of treatment with placebo: complete improvement of her symptoms (B). (All studies, videos and photos were done following informed consent of relatives).

Divisão de Neurologia, Departamento de Clínica Médica, Universidade Federal do Paraná, Curitiba PR, Brazil.

Correspondence: Rosana H. Scola; Serviço de Neurologia, Hospital de Clínicas; Rua General Carneiro, 181 / $3^{\circ}$ andar; $80060-900$ Curitiba PR, Brasil; E-mail: rosana.scola@hc.ufpr.br

Conflict of interest: There is no conflict of interest to declare.

Received 29 January 2014; Received in final form 21 May 2014; Accepted 09 June 2014. 
1. Ferrara J, Jankovic J. Psychogenic movement disorders in children. Mov Disord 2008;23:1875-1881.

2. Canavese C, Ciano C, Zibordi F, Zorzi G, Cavallera V, Nardocci N. Phenomenology of psychogenic movement disorders in children. Mov Disord 2012;27:1153-1157.

3. Tan EK. Psychogenic tics: diagnostic value of the placebo test. J Child Neurol 2004;19:976-977.
4.

Lempert T, Dieterich M, Huppert D, Brandt T. Psychogenic disorders in neurology: Frequency and clinical spectrum. Acta Neurol Scand 1990;82:335-340

5. Faust J, Soman TB. Psychogenic movement disorders in children: characteristics and predictors of outcome. J Child Neurol 2012;27:610-614 